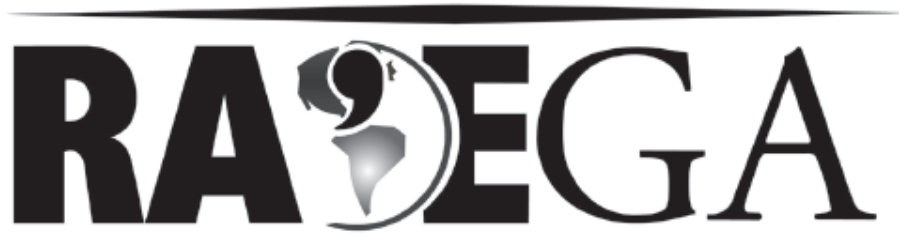

O ESPAÇO GEOGRÁFICO EM ANÁLISE

\title{
PRECARIZAÇÃO DO TRABALHO - O MICROCRÉDITO COMO POSSIBILIDADE DE DESENVOLVIMENTO SOCIOESPACIAL
}

\author{
PRECARIOUS WORK - MICROCREDIT AS A \\ POSSIBILITY OF SOCIO-SPATIAL DEVELOPMENT
}

\author{
Rafael Mendes MOREIRA ${ }^{1}$ \\ Ideni Terezinha ANTONELLO ${ }^{2}$
}

\section{RESUMO}

O processo de precarização do trabalho diz respeito à situação cada vez mais precária que os trabalhadores estão submetidos desde 0 advento do capitalismo como principal sistema econômico no mundo, principalmente, com as profundas mudanças ocorridas nas formas organizativas do trabalho, após a década de 1970, fazendo com que um grande número de pessoas tenha que se submeter a atividades e ocupações no setor informal da economia. No entanto, podemos observar tentativas de políticas públicas que vem sendo feitas para atender especificamente este público, como o oferecimento de microcréditos. Este artigo tem por objetivo levantar a hipótese de que 0 microcrédito pode atuar no sentido de amenizar as consequências desse processo de precarização do trabalho, contribuindo para um maior desenvolvimento socioespacial.

Palavras-chave: precarização do trabalho; microcrédito; desenvolvimento socioespacial.

\footnotetext{
${ }^{1}$ Mestrando no Programa de Pós Graduação em Geografia na Universidade Estadual de Londrina. E-mail: rafael_mendes_moreira@yahoo.com.br

2 Prof ${ }^{a}$. Doutora do Curso de Graduação e Pós-Graduação de Geografia da Universidade Estadual de Londrina. E-mail: antonello@uol.br
} 


\section{ABSTRACT}

The process of precarious work deals with the situation becoming more precarious workers are subjected since the advent of capitalism as the main economic system in the world, especially with the profound changes in organizational forms of work, after a decade of 1970, causing a large number of people have to undergo activities and occupations in the informal sector. However, we see attempts at public policies that have been made to specifically address this audience, as the offer of microcredit. This article aims to raise the hypothesis that microcredit can act to mitigate the consequences of this process of precarious employment, contributing to a greater socio-spatial.

Keywords: precarious work; microcredit; development socio-spatial.

\section{INTRODUÇÃO}

A temática a respeito da categoria trabalho vem suscitando diversos debates acadêmicos ao longo dos anos. Diversos são os autores que buscam um maior entendimento sobre o conceito de trabalho e sobre as transformações históricas ocorridas no "mundo do trabalho" (ALVES, 2005; FORRESTER, 1997; GORZ, 2001; SINGER, 2003; THOMAZ JR., 2004 entre outros). Essas análises pautam-se tanto no recorte temporal alicerçado nas Divisões Internacionais do Trabalho, bem como se remetem as mudanças diretas presenciadas no sistema produtivo, condições de empregos e desemprego, táticas empresariais atuais de "controle do trabalho" (HARVEY, 1992).

Dentro dessa discussão, o processo de transformação do trabalho ao longo das décadas foi e vem sendo alvo de pesquisas, as quais permitem chegar à conclusão de que as empresas estão explorando de forma intensa os trabalhadores, uma vez que estão perdendo seu poder de barganha e de reivindicação de melhores condições e conteúdos de trabalho, em um processo conhecido como precarização do trabalho. O desdobramento para o mundo do trabalho deste processo pode ser visualizado nas seguintes condições: aumento da alienação do trabalho, aumento do estranhamento e da exploração do trabalhador, perda da consciência de classe por parte dos trabalhadores, 
enfraquecimento dos sindicatos, surgimento de formas alternativas de trabalho e geração de renda, como trabalho informal, trabalho temporário, trabalho em tempo parcial, entre outros.

Em períodos históricos distintos autores propuseram sugestões e ideias para amenizar ou até mesmo modificar radicalmente a situação de exploração do trabalhador pelo capital, como o fim da propriedade privada e a tomada das forças produtivas pelos trabalhadores (MARX, 2006) implantação da ideia do "tempo liberado", com trabalhos de menor duração de tempo e consequente aumento do número de postos de trabalho, em que os trabalhadores, com maior tempo disponível, poderiam alcançar autonomia existencial (GORZ, 2001), e até mesmo substituição total da categoria trabalho como norteadora do desenvolvimento e das relações sociais, posto que esta não é mais capaz de gerar renda e garantir a sobrevivência de todas as pessoas (FORRESTER, 1997).

É justamente com o intuito e a perspectiva de contribuir para a discussão de alternativas que visem amenizar as consequências do processo de precarização do trabalho que buscamos formas de abordar e analisar a temática, para oferecer subsídios para a aplicação de políticas públicas voltadas para a população que mais sofre com esse processo, ou seja, as pessoas com menor escolaridade, com menor nível de renda, e/ou com poucas possibilidades de conseguir um emprego formal. Nesse contexto, destacamos as políticas de microcrédito.

Operações de microcrédito são operações de empréstimo de pequenos valores, a juros reduzidos, normalmente direcionados as pessoas com baixo nível de renda. Tem como objetivo ser investido de forma empreendedora, ou seja, parte do pressuposto de que o tomador irá investir esse dinheiro em alguma atividade que proporcionará melhor renda ou investir para melhorar a atividade já exercida.

Este artigo tem com escopo suscitar o debate sobre o papel que 0 microcrédito como política pública pode exercer sobre o processo de precarização do trabalho, levantando a hipótese que tal ferramenta pode ajudar a amenizar as consequências de tal processo, contribuindo para uma melhor 
qualidade de vida de seus tomadores, por conseguinte para se atingir um desenvolvimento socioespacial. Salientamos que o procedimento metodológico da pesquisa constituiu-se em uma revisão bibliográfica sobre a temática proposta com o intuito de se realizar uma reflexão teórica sobre as discussões atuais sobre as transformações no mundo do trabalho. Bem como realizamos uma investigação sobre a configuração da política pública de microcrédito. Dessa forma, o presente artigo está estruturado em dois eixos centrais o primeiro voltado para a concepção de trabalho com o intuito de apreender as transformações da forma como o trabalho se apresenta para o trabalhador para adentrar na discussão sobre as mudanças ocorridas no sistema de regulação do trabalho como a passagem do sistema de regulação do trabalho fordista para o regime de acumulação flexível, fundamental para entendermos os atuais processos de precarização do trabalho. No segundo eixo discutiremos sobre a possibilidade das políticas de microcrédito amenizar a situação de precariedade do trabalho enfrentada pelos trabalhadores que se encontram excluídos do mercado de trabalho de formal.

\section{O PROCESSO DE PRECARIZAÇÃO DO TRABALHO - DO FORDISMO AO REGIME DE ACUMULAÇÃO FLEXÍVEL}

Consideramos fundamental fazer uma reflexão sobre a concepção de trabalho antes de introduzir a questão da precarização, no sentido de apreender o processo de transformação do sentido do trabalho ao longo da relação homem- trabalho, ou seja, de que forma o trabalho vai se tornando estranho ao trabalhador. Pois como elucida Marx (1996, p. 297) “Antes de tudo, o trabalho é um processo entre o homem e a Natureza, um processo em que o homem, por sua própria ação, media, regula e controla seu metabolismo com a natureza". Assim, podemos entender o trabalho como sendo fruto do esforço humano na sua intermediação com os elementos da natureza, a fim de satisfazer suas necessidades. De acordo com essa concepção é possível incluir como trabalho as atividades que o homem faz para garantir sua sobrevivência, ou seja, as atividades mais elementares feitas há milhares de 
anos. Dessa forma, o trabalho existiria anteriormente a qualquer forma de comercialização ou produção voltada a fins mercantis, e até mesmo antes de qualquer tipo de organização social. Marx confirma isso ao afirmar que 0 trabalho, no início, independe de qualquer forma social determinada, sendo considerado uma "[...] atividade orientada a um fim [...]" (ibid., p. 297-298). Por conseguinte, para Marx o trabalho (concreto) não é, em seu aspecto intrínseco, uma mercadoria, nem tampouco age única e exclusivamente para obter dinheiro/salário, uma vez que surgiu antes deste, portanto esta forma de trabalho não se vincula ao trabalho alienado que será o pressuposto do modo de produção capitalista.

A leitura de Gorz (2001) destaca outros elementos presente na forma de trabalho concreto, pois o autor busca definir o que não seria 0 trabalho concreto nos dias atuais, como a imposição do trabalho alienado (trabalho assalariado). Assim,

O "trabalho", no sentido contemporâneo do termo, não se confunde nem com os afazeres, repetidos dia após dia, necessários à manutenção e à reprodução da vida de cada um; nem com o labor, por mais penoso que seja, que um indivíduo realiza para cumprir uma tarefa da qual ele mesmo e seus próximos serão os destinatários e os beneficiários; nem com o que o empreendemos por conta própria, sem medir nosso tempo e esforço, cuja finalidade só interessa a nós mesmos e que ninguém poderia realizar em nosso lugar. Se chamamos a essas atividades "trabalho" - o "trabalho doméstico", o "trabalho do artista", o "trabalho" de autoprodução -, fazemo-lo em um sentido radicalmente diverso do sentido que se empresta à noção de trabalho, fundamento da existência da sociedade, ao mesmo tempo sua essência e sua finalidade última. (GORZ, 2001, p. 21)

Gorz revelava na sua análise o ponto central que diferencia o trabalho voltado para uma finalidade concreta do trabalho que encerra em si mesmo uma finalidade que é o salário, isto é, a relação do homem com o trabalho, na qual atualmente, pauta-se em uma relação de troca, sendo assim:

[...] a característica mais importante desse trabalho - aquele que "temos", "procuramos", "oferecemos" - é ser uma atividade que se realiza na esfera pública, solicitada, definida, e 
reconhecida útil por outros além de nós e, a este título, remunerada. É pelo trabalho remunerado (mais particularmente, pelo trabalho assalariado) que pertencemos à esfera pública, adquirimos uma existência e uma identidade sociais (isto é, uma profissão), inserimo-nos em uma rede de relações e de intercâmbios, onde a outros somos equiparados e sobre os quais vemos conferidos certos direitos, em troca de certos deveres. (Ibid., p. 21, grifo do autor.)

Podemos perceber que Gorz enfoca a concepção de trabalho como atividade desenvolvida em troca de uma remuneração, um salário. Observamos uma mudança substancial quanto ao conteúdo do trabalho desde a relação direta do homem como a natureza, na qual o homem colocava em prática a sua corporalidade para atingir um objetivo direto que fica implícita a ideia de que o trabalho, em sua forma concreta, pode e deve ser provido para os fins de quem o realiza, ou seja, sem pressupor uma relação de remuneração e apropriação do produto do trabalho. Para um conteúdo de trabalho que subentende uma relação de subordinação as relações de produção permeadas pelo poder do capital, nas quais o trabalho passa por um processo de estranhamento, uma vez que o que o trabalhador irá colocar em ação não é o seu trabalho e sim a sua força de trabalho, uma mercadoria. Como salienta Marx: "O que o operário vende não é diretamente o seu trabalho, mas a sua força de trabalho, cedendo temporariamente, ao capitalista o direito de dispor dela" (s/d, p.273). Nessa situação o autor elucida que o trabalhador moderno, ou seja, o "trabalho livre", "[...] não pertence nem a um proprietário nem a terra, mas $8,10,15,18$ horas de sua vida diária pertencem a quem as compra" (Ibid, p.63).

Podemos considerar que tanto o trabalho feito para si como a renda gerada pela venda da força de trabalho irá permitir que o trabalhador sobreviva, porém, com conteúdos de trabalho (e seu propósito) radicalmente diferentes entre si.

Destacamos as análises Paul Singer (2003) sobre a questão do trabalho na contemporaneidade, porém o autor utiliza mais a expressão emprego, que está intimamente ligado a noção de trabalho. Singer (2003, p. 12) define emprego como sendo a compra da força de trabalho ou da capacidade de 
produzir de um trabalhador por um empregador. Com base nesse conceito, critica o termo oferta de emprego, pois na realidade, quem oferece alguma coisa, a sua força de trabalho, é o trabalhador, sendo que o empregador seria o comprador desta "mercadoria", por conseguinte, não existe uma oferta de emprego, mas um mercado de trabalho.

O autor ainda faz uma importante diferenciação sobre os conceitos de emprego e ocupação, esta última sendo entendida como "[...] toda atividade que proporciona sustento a quem a exerce." (Ibid., p. 14), as quais compreendem as atividades autônomas que segundo o autor aumentam na medida em que o capitalismo reduz o volume da força de trabalho que emprega. Assim, o emprego subentende a venda da força de trabalho para o capital, enquanto que a ocupação não se encontra subordinada diretamente a esta relação.

Entendemos que emprego e ocupação são formas distintas, mas não menos expressivas, da atualidade do mundo do trabalho. Enquanto em um subentende-se a contratação de um (trabalhador) perante outro (empregador), o outro engloba as diversas formas autônomas de atividades que possam gerar renda para o sustento de alguém, sem, necessariamente, vender sua força de trabalho e permitir a apropriação de seu esforço por outro, em troca de um salário.

A noção de trabalho (ocupação) vincula-se ao sentido de não expropriação do produto por outrem permeada pela relação social de produção, no entanto não se constitui na mesma relação apontada por Marx (1996) quando este afirma que o trabalho (em sua forma concreta) é uma atividade orientada para um fim, uma vez que às atividades autônomas (ocupações) estarem ligadas, atualmente, a geração de valores de troca, tendo como fins únicos a comercialização e geração de renda para quem as produz ou as vende, sejam mercadorias ou serviços.

A análise desses três autores demonstra a mudança de conteúdo do trabalho ao longo do tempo com a imposição da lógica capitalista de produção, todavia cabe ressaltamos que essa transformação no sentido do trabalho ancora-se no que Weber (1997) denominou de "racionalidade econômica" que 
é indiferente a outros valores e outros objetivos que não os da cumulação do capital.

Essa lógica econômica busca racionalizar a produção, dominar os custos, torná-los rigorosamente calculável e previsível, graças à quantificação e normatização de seus elementos. A racionalidade econômica veio se contrapor a sociedade existente anteriormente (pré-capitalista) regida por tradições "irracionais" do ponto de vista econômico, portanto, contrário aos interesses capitalistas; mas essa sociedade, que em nada almejava os ideais capitalistas de acumulação e lucro, era o modo de vida vivenciado e apreciado pela sociedade à época.

Em outras palavras, não existia o rigor de calcular o preço de cada parte do processo produtivo, bem como estabelecer um preço da mão de obra, pois a acumulação da maior quantidade de lucro não era um fim a ser perseguido. Tanto as tradições como outros tipos de racionalidade impediram durante algum tempo o desenvolvimento da racionalidade econômica, até esta ganhar forças e submeter todas as outras racionalidades aos seus desejos. A racionalidade econômica precisou calcular salários, para poder calcular rendimentos e prever os lucros; além, é claro, de convencer os trabalhadores a trabalhar servindo fins que Ihes eram estranhos e indiferentes. Assim,

[...] o reducionismo unidimensional da racionalidade econômica própria do capitalismo teria um alcance potencialmente emancipador porque faz tábua rasa de todos os valores e fins irracionais do ponto de vista econômico e só mantém, entre os indivíduos, relações monetárias, entre as classes, relações de forças, entre o homem e a natureza uma relação instrumental, fazendo nascer com isso uma classe de operários-proletários totalmente despossuídos, reduzidos a nada mais que a força de trabalho indefinidamente intercambiável, sem nenhum interesse particular a defender. (GORZ, 2001, p. 27 - 28)

O capitalismo trouxe consigo a alienação do trabalhador e seu estranhamento ao trabalho. Em outras palavras, a propriedade privada dos meios de produção fez com que aqueles que não possuíssem meios de produção tivessem como única alternativa de sobrevivência a venda da sua força de trabalho, em troca de um salário que garantisse a sua sobrevivência. 
Dessa forma, o trabalhador não trabalha mais para si, não trabalha para produzir coisas para satisfazer suas necessidades, trabalha almejando apenas um salário, ou seja, o produto de seu trabalho não é seu, é expropriado pelo capitalista que lucra com o resultado do trabalho do outro. $O$ estranhamento quanto ao trabalho está justamente no fato de que o trabalhador não trabalha porque quer, não tem interesse no resultado de seu trabalho e tão pouco sabe para que serve o seu trabalho, de forma que, trabalhando unicamente por um salário, seu trabalho fica totalmente estranho a si mesmo. Sobre isso, Marx (2006, p. 112, grifos do autor) afirma que "[...] o trabalhador se relaciona com o produto do seu trabalho como a um objeto estranho".

Nesse sentido, Harvey (1992, p. 118 e 119) salienta que uma das principais dificuldades encontradas pelo capitalismo foi justamente garantir que os produtos, e consequentemente, 0 trabalho feito pelos trabalhadores pudessem ser expropriados pelos capitalistas. Para isso, Harvey afirma que foi necessária uma "[...] disciplinação da força de trabalho para os propósitos da acumulação do capital", em um processo que denominou de "controle do trabalho" (Ibid.,p. 119). Percebemos a relação direta entre a concepção de "racionalidade econômica" defendida por Weber (1997) e o processo de disciplinação da força de trabalho enfocada por Harvey (1992).

Ressaltamos que o foco da presente análise volta-se a forma de controle do processo de trabalho no sistema produtivo conhecido como fordismotaylorismo e do seu sucedâneo o denominado modelo japonês. O primeiro constituiu-se mediante a implantação da linha de montagem, por conseguinte as tarefas repetitivas feitos pelos trabalhadores, reguladas rigidamente, não necessitando de seu trabalho intelectual, apenas de seu trabalho mecânicobraçal. Foi nesse sistema também que teve início à disseminação do salário fixo e da jornada de oito horas de trabalho. Assim, o fordismo não foi somente um processo de disciplinação do trabalhador à linha de montagem, mas também tinha o intuito de dar ao trabalhador tempo e renda para consumir 0 que se estava produzindo em massa pelas grandes corporações, isto é, produção em massa deveria ter consumo em massa. Nesse sentido, o fordismo 
foi uma reviravolta nos meios de produção e produtividade, mas também uma "revolução" na sociedade, ao estimular o consumo de massa.

Mesmo sendo desenvolvido em décadas anteriores, é somente no pós Segunda Guerra Mundial que o fordismo alcança um amadurecimento a ponto de sair dos Estados Unidos e começar a se espalhar pela Europa. Evidentemente isso não aconteceu por acaso, posto que o financiamento da reconstrução dos países da Europa, encabeçado pelos Estados Unidos, ocorreu na condição de aquele continente se abrir para as grandes firmas e corporações estadunidenses, disseminando-se assim o modelo produtivo fordista.

Destacamos outra estratégia essencial para a aceitação e consequente expansão do sistema de regulação do trabalho fordista que foi a cooptação dos sindicatos. O sindicalismo antes da Segunda Guerra Mundial era forte, levando em consideração que a concentração de trabalhadores aumenta o poder destes e de suas entidades representativas. No pós-guerra, os sindicatos foram aceitos pelas empresas na medida em que colaborassem com a administração no sentido de influenciar seus membros para aumentar a produtividade, e controlassem estes utilizando compensações de ganhos de salários (HARVEY, 1992, p. 129). Nesse aspecto, a "derrota" dos movimentos operários no pósguerra foi característica fundamental para o controle do trabalho que permitiu $o$ desenvolvimento do fordismo.

O sistema fordista manteve-se estável até o início da crise mundial no início da década de 1970. Até essa data, o fordismo tinha assegurado bons índices de crescimento econômico e relativa melhoria nas condições e salários dos trabalhadores. Porém, as contradições existentes dentro do capitalismo regido pelo sistema fordista, ocasionadas sobretudo pela rigidez produtiva, levaram inevitavelmente a queda do próprio sistema.

Segundo Harvey (1992) essa rigidez sistêmica impedia uma flexibilização produtiva, operava sob a lógica de um crescimento estável dos mercados consumidores e era configurada por uma significativa organização e conseqüente poder dos trabalhadores, impedindo maiores artimanhas por parte dos industriais para driblar a rigidez. O Estado assume o papel de alimentar o 
regime de acumulação do capital fordista mediante programas assistencialistas (saúde, educação, habitação) para os trabalhadores com o intuito de arcar de forma indireta com parte da renda dos mesmos, e assim desobrigando o capital de manter melhores salários.

Nesse contexto, é engendrada a crise da acumulação do capital, resultado da recessão econômica conjugada com o choque do petróleo, o que leva o enfraquecimento padrão fordista perante a crise de reprodução do capital, por conseguinte a sua substituição. Assim nas décadas de 1970 e 1980 ocorre "[...] um conturbado período de reestruturação econômica e de reajustamento social e político" (HARVEY, 1992, p.140).

O regime de acumulação do capital que passa a se estabelecer nesse processo é denominado de diversas formas, por exemplo Harvey (1992) designa de "acumulação flexível" e Alves (2005) usa o termo "toyotismo"; não é incomum também encontrarmos a terminologia "pós-fordismo". No entanto, todas as análises buscam entender este processo de transição, o qual tem como resultado profundas mudanças não só para o mundo do trabalho, mas para toda a sociedade. As palavras de Harvey elucidam o que se constitui a acumulação flexível:

[...] é marcada por um confronto direto com a rigidez do fordismo. Ela se apóia na flexibilização dos processos de trabalho, dos mercados de trabalho, dos produtos e padrões de consumo. Caracteriza-se pelo surgimento de setores de produção inteiramente novos, novas maneiras de fornecimento de serviços financeiros, novos mercados e, sobretudo, taxas altamente intensificadas de inovação comercial, tecnológica e organizacional. A acumulação flexível envolve rápidas mudanças dos padrões de desenvolvimento desigual, tanto entre setores como entre regiões geográficas. (1992, p. 140)

Observamos que o novo regime vem contrastar diretamente com 0 sistema produtivo rígido fordista, buscando formas flexíveis de adentrar no mercado, na produção dos produtos, nos padrões de consumo e no mundo do trabalho. Os sistemas produtivos são completamente modificados, agora equipados com novas maquinarias que desempenham novas e variadas funções. A inovação também se faz sentir nos produtos e no aspecto 
organizacional da empresa, que agora utiliza novas abordagens para produzir, para se relacionar com fornecedores, para garantir a boa eficiência dos trabalhadores, entre outras inovações.

Cabe destacarmos que esses novos padrões organizacionais e novos critérios de tomadas de decisões adotados pelas empresas pautam-se nos avanços dos meios de telecomunicações e de transportes. A utilização de satélites e o conseqüente desenvolvimento de tecnologias que permitem a comunicação praticamente instantânea alteraram completamente o universo empresarial, o qual tornou essas ferramentas uma arma poderosa no processo de tomada de decisões, capaz de influenciar diretamente na produção, no nicho de mercado e nas perspectivas de mercado.

Com a flexibilização do processo produtivo, este se torna mais complexo, e a mão de obra exigida para trabalhar nesse processo necessita ser de maior instrução, ter cursos especializados, ou seja, precisa de maior qualificação. O conteúdo do trabalho também é drasticamente modificado no regime de acumulação flexível. Enquanto o fordismo necessitava de homens unicamente para desempenhar atividades mecânicas, ou seja, precisava do saber fazer operário, o novo regime de acumulação busca trabalhadores polivalentes, que possam desempenhar mais de uma função, sendo que, nesse novo regime de acumulação, o aspecto intelectual-criativo passa a ser o item mais valorizado nos trabalhadores.

Essas transformações ocorreram justamente em uma época em que uma das facetas da crise do capitalismo era justamente a intensificação da coisificação do trabalho do homem, em que este era utilizado unicamente como uma coisa, como a peça de uma engrenagem de uma máquina, de forma que executava movimentos repetitivos desprovidos de qualquer habilidade intelectual. Assim, ao mesmo tempo em que o fordismo enquanto sistema organizacional estava entrando em colapso, a classe trabalhadora organizada almejava novas formas e novos conteúdos de trabalho.

O regime de acumulação flexível foi desenvolvido com o intuito de se estabelecer novas formas de exploração e controle dos trabalhadores. Para isso, utilizou-se de discursos ideológicos que faziam os trabalhadores 
acreditarem que o novo sistema vinha justamente atender suas expectativas e desejos. No entanto, essa aparente aceitação dos capitalistas quanto ao atendimento dos interesses dos trabalhadores se deu unicamente com 0 objetivo de reinventar o processo de acumulação do capital, de forma que permitisse a continuação de sua reprodução, propiciada por um maior controle do trabalho.

Uma das formas de organização do trabalho desse novo sistema é a divisão de trabalhadores em grupos, em que cada grupo seria responsável pela elaboração, criação e resolução de problemas em uma determinada etapa do processo produtivo. Dessa forma, cada trabalhador do grupo seria responsável por todo um processo dentro de uma cadeia produtiva, sem hierarquias dentro do grupo, ou seja, todos seriam livres para propor ideias e soluções de melhorias no processo produtivo. Esse último ponto redunda na estratégia utilizada pelas empresas que é justamente a possibilidade de participação dos trabalhadores no processo de melhora da produção. Agora, todos os trabalhadores são responsáveis pelo processo produtivo, de forma que todos podem dar sugestões de melhorias para que aumente a eficiência de seus trabalhos.

Essas características do novo modelo de controle do trabalho segundo Wolff (2005, p. 180) podem ser sintetizadas nos Programas de Qualidade Total. Tais programas, assim como todas as outras inovações colocadas em prática no regime de acumulação flexível, visavam aumentar o engajamento dos trabalhadores para com a empresa, objetivando que o trabalhador sinta-se sujeito do seu próprio trabalho, orgulhoso de seu ofício e satisfeito em ajudar a empresa. Esses novos trabalhadores são dotados de habilidades mais complexas que no regime fordista, uma vez que seu trabalho exige seu esforço intelectual, é mais comprometido com a empresa e engajado com seus objetivos.

Longe de ser a perfeita adequação entre interesses das empresas e desejos dos trabalhadores, Wolff afirma que as novas abordagens na gestão do trabalho atuam "[...] para além da expropriação do saber operário, pela expropriação e objetivação das capacidades cognitivas, de criação ou prévia 
ideação, de iniciativa, enfim, pela 'apropriação da dimensão intelectual da atividade criativa'." (2005, p. 173). Assim, além do capital se usar da expropriação da capacidade de agir do trabalhador, passa também a expropriar o pensar do trabalhador (Ibid., p. 174), aproveitando-se de suas capacidades físicas e agora também das psicológicas, única e exclusivamente para aumentar seu poder na dinâmica competitiva capitalista, a fim de auferir maiores lucros. Wolff (2005) diz que essa é outra forma de dominação e controle dos trabalhadores por parte dos capitalistas, mas muito mais sutil e dissimulada do que no sistema fordista, pois está mascarada pela aparente autonomia e junção entre concepção e execução no trabalho. Assim, essas novas formas de dominação são qualitativamente superiores em relação ao fordismo.

A questão da autonomia conseguida pelos trabalhadores no regime de acumulação flexível é questionada pela mesma autora, que não enxerga autonomia em atividades previamente determinadas e com objetivos e finalidades alheias ao trabalhador, de interesse unicamente da empresa, de forma que a queda das barreiras entre planejamento e execução seja apenas um discurso utilizado como forma de manipulação. Assim, podemos afirmar que pequenos graus de autonomia no trabalho não significam necessariamente autonomia do trabalho.

O discurso do novo regime de acumulação flexível para convencer e engajar os trabalhadores aos objetivos da empresa é de que está havendo uma humanização do trabalho do homem, com a inserção de novos conteúdos que permitem um maior e melhor desenvolvimento do homem no trabalho. No entanto, Gorz (2001, p. 72 e 73) demonstra bem qual o real objetivo e a estratégia utilizada pelos capitalistas para conseguir convencer os trabalhadores a se doarem as empresas:

A figura desse trabalhador de novo tipo, orgulhoso de seu ofício, soberano em seu trabalho, capaz de evoluir no mesmo passo da técnica, tal figura não nasceu de uma concessão tardia do patronato ao humanismo do trabalho. Corresponde, antes, a uma necessidade originada das transformações da técnica. [...] Bastou, para tanto, que retomasse por sua conta os valores da utopia do trabalho: domínio (quer dizer, 
reapropriação técnica), pelos trabalhadores, dos meios de produção, desenvolvimento pleno das capacidades individuais no trabalho, valorização do ofício e da ética profissional. (grifo do autor)

Diante desta análise, fica claro que o sistema de acumulação flexível é, antes de tudo, uma nova estratégia do capital para garantir sua reprodução. Dessa forma, consideramos o discurso utilizado, de humanização do trabalho, como sendo de caráter manipulatório e ideológico, sendo que, na realidade, produz um quadro de extrema precarização do trabalho para a maioria dos trabalhadores, que são submetidos a condições degradantes e desumanas para garantir sua sobrevivência, enquanto uma pequena minoria consegue atingir altos níveis de padrão de vida. Tal situação fica clara nas palavras de Gorz:

No momento em que uma fração privilegiada da classe operária pode aceder ao politecnismo, à autonomia no trabalho e ao enriquecimento permanente de suas competências, tudo o que idealizavam as correntes auto-gestionárias no interior do movimento operário, as condições nas quais este ideal parece prestes a se realizar, mudam radicalmente seu sentido. Não é a classe operária que acede a possibilidades de autoorganização e a crescentes poderes técnicos; é um pequeno núcleo de trabalhadores privilegiados que é integrado em empresas de novo tipo, às custas da marginalização e da precarização de uma massa de pessoas que passam de um trabalho ingrato e ocasional a um trabalho qualquer, sem nenhum interesse, com freqüência reduzidas a disputarem o privilégio de vender serviços pessoais (inclusive de engraxate, de empregado ou empregada doméstica) àqueles e àquelas que conservam uma renda estável. (Ibid., p. 76, gripo do autor)

Percebemos que o processo de precarização do trabalho diz respeito à situação cada vez mais precária e a constante perda de direitos que os trabalhadores estão submetidos desde o advento do capitalismo como principal sistema econômico no mundo, principalmente após a década de 1970 com o regime de acumulação flexível. Segundo Vasapollo (2005, p. 61), "[...] é justamente com a flexibilização imposta pelas regras de eficiência das empresas que se chega à condição de trabalho precarizado, não continuado e temporário". 
Sob o discurso de que os trabalhadores precisam ser cada vez mais qualificados, treinados e com conhecimentos múltiplos, o capitalismo esconde suas contradições intrínsecas, sobretudo o fato de precisar de cada vez menos trabalhadores para ser auto-sustentado e garantir sua reprodução. Tal fato pode ser observado mediante a existência nos dias de hoje de um imenso exército de reserva de trabalhadores altamente qualificados, com cursos superiores e até mesmo pós-graduações. Esse fenômeno reflete no fato que empregadores exigem altos níveis de escolarização para realizar tarefas e trabalhos relativamente simples. Sobre isso, Pochmann afirma que:

\footnotetext{
Em geral, o aumento dos índices de escolaridade não aponta necessariamente para a existência de requisitos adicionais no conteúdo dos postos de trabalho, mas possivelmente para a demanda insuficiente de trabalho por parte das empresas. Com o maior desemprego, os empresários terminam por privilegiar a contratação sobretudo dos trabalhadores mais escolarizados, independentemente de haver mudanças no conteúdo do trabalho. (2001, p. 63)
}

Diante deste quadro, uma primeira forma de expressão da precarização do trabalho seria o desemprego estrutural. Este desemprego, no entanto, parece ser inerente a nova reestruturação produtiva do capitalismo, o regime de acumulação flexível, posto que, desde seu advento, o número relativo de empregos no setor produtivo vem decrescendo, ao passo que o setor de serviços vem desempenhando um papel fundamental na geração de emprego e renda para a população, crescendo de forma surpreendente. Não coincidentemente, o número de pessoas que desempenham atividades informais é maior no setor de serviços, ou seja, este setor acaba sendo uma das últimas alternativas de obtenção de renda para quem não consegue se inserir no mercado formal de trabalho. Sendo assim, a falta de empregos é amenizada sobretudo pela expansão e inchamento do setor de serviços, principalmente devido às atividades informais.

Uma das possíveis respostas para esse vertiginoso crescimento do setor de serviços pode ser encontrado nas novas características empresariais que 0 processo produtivo de acumulação flexível trouxe. Esse processo é a 
descentralização de capitais, via terceirização (SINGER, 2003, p. 17). Tal fenômeno configura-se com grandes empresas verticais, nas quais ocorre a separação das atividades complementares, as mesmas são adquiridas em outras empresas terceirizadas. Dessa forma, Singer (2003) levanta a hipótese de estar ocorrendo uma mudança paradigmática da reprodução capitalista: se o capital descentralizado prefere explorar trabalho mediante a compra de serviços, ao invés de força de trabalho, o capitalismo está sofrendo uma transformação radical e, assim seria um erro diagnosticar a crescente exclusão social como resultado do desemprego.

Porém, não é somente com o desemprego que vemos as condições precárias do mundo do trabalho. Podemos percebê-la também em trabalhadores empregados e naqueles que exercem alguma ocupação (conforme a concepção de SINGER, 2003) mesmo que no setor informal. O quadro de precarização se cristaliza no salário do trabalhador que se reduz, assim este precisa trabalhar mais horas durante o dia e mais dias na semana para garantir sua sobrevivência. Se expressa na perda de direitos trabalhistas conseguidos historicamente pela classe trabalhadora, como férias, descanso remunerado semanal, falta médica remunerada, contribuição previdenciária, estabilidade, entre outros. Se traduz nas múltiplas formas de trabalhos precários que surgem na falta de alternativas de conseguir renda em um emprego formal (registrado).

As diferentes formas de trabalho que os trabalhadores se submetem para conseguir sobreviver na lógica capitalista de reestruturação produtiva, como trabalho temporário, em tempo parcial, informal, entre outros, Thomaz Jr. (2004, p. 12) designa de "plasticidade do trabalho". Já Vasapollo (2005, p. 60) ao analisar a realidade vivenciada pelos trabalhadores da União Européia utiliza a expressão "trabalho atípico" para tratar do processo de precarização do trabalho e apresenta a situação que estes trabalhadores estão submetidos, como por exemplo, planos de recolocação profissional, contrato temporário inclusive para idosos, terceirização das atividades (subcontratado), trabalho por turno, por escala, tempo parcial, horário flexível, além do mal-estar do trabalho - medo de perder o posto. 
A descentralização do processo produtivo via terceirização pode ser considerado mais uma estratégia engendrada pelas empresas para um maior controle do trabalho e maximização dos lucros. Com a terceirização, as empresas têm menos responsabilidades com contratos e registros de trabalho, menos trabalhadores atuando em um mesmo espaço (o que, consequentemente, diminui o poder de organização dos trabalhadores), preferindo comprar determinados produtos/serviços de outras empresas ao invés de eles mesmos manterem um efetivo de força de trabalho dentro de suas linhas produtivas para realizar determinadas tarefas. Assim, Singer (2003, p. 25) afirma que, com a terceirização, "[...] o ex-empregador ganha novos graus de liberdade, e os ex-empregados perdem a segurança que tinham".

Para Harvey (1992) a acumulação flexível permite um maior controle do trabalho, e veio justamente em uma época de profunda crise e desemprego. Ainda segundo o autor, esse novo sistema parece aumentar os níveis de desemprego estrutural, ocasionar rápidas mudanças de habilidades, pequenos ganhos de salário real para determinada categoria de trabalhadores e 0 enfraquecimento do poder sindical. Além disso, a partir de 1972, com a reestruturação produtiva e organizacional se consolidando, a acumulação flexível teve como conseqüência o aumento do número de empregos no setor de serviços. No entanto, o autor aponta outras hipóteses para esse fenômeno, como por exemplo o crescimento da subcontratação e consultoria (atividades antes internalizadas e realizadas pelas próprias empresas), ou necessidade de se alterar o padrão de produção para bens com tempo de giro menor.

É justamente no setor informal de prestação de serviços que se encontra a pior face da precarização do trabalho, uma vez que podemos observar diversas formas de trabalhos precários, ocasionados principalmente pela falta de oportunidades dessas pessoas em obterem um emprego formal, devido, normalmente, a sua baixa escolaridade. Todavia não estamos entrando no mérito sobre a qualidade dos empregos que uma escolarização melhor poderia proporcionar, e sim que, com uma maior escolarização, essas pessoas teriam maiores chances de conseguir um emprego formal, independente de ser um emprego considerado bom ou ruim. Exemplos comuns desses trabalhadores 
precarizados, normalmente inseridos no mercado informal, são os camelôs, vendedores autônomos, engraxates de rua, pessoas oferecendo serviços e produtos em semáforos, vendedores de salgados/bolos/café que perambulam a cidade com suas bicicletas atrás de clientes, "flanelinhas", panfleteiros, empregadas domésticas, eletricistas, encanadores, entre outros. São pessoas inseridas em um contexto de carência de criação de postos de trabalho para todos, devido ao sistema de reprodução do capital vigente

No entanto, como já dito anteriormente, os trabalhadores devidamente registrados também sofrem o processo de precarização do trabalho. Trabalhadores no setor comercial, por exemplo, estão submetidos a pressões e metas de vendas cada vez mais abusivas por parte de seus empregadores. Diversas categorias profissionais são obrigadas a trabalhar além da sua jornada de trabalho, muitas vezes sem ganhar absolutamente nada para isso. Atualmente, além do trabalho manual, as empresas buscam a apropriação do trabalho intelectual do trabalhador, ou seja, "não é somente o 'saber' e o 'fazer' do trabalhador que são capturados, mas também a sua capacidade de se dispor intelectual e afetivamente em benefício da equipe, cooperando assim com a lógica de valorização do capital" (OLIVEIRA, 2004, p. 81). Ou seja, a forma de exploração do novo tipo de acumulação flexível é ainda mais perversa do que a visualizada anteriormente.

Os mecanismos de controle do trabalho segundo Wolff $(2005$, p. 232) se encontram na imposição do autocontrole exigido do trabalhador e que está presente implicitamente no sistema de acumulação flexível, o qual age como um fiscalizador psicológico dentro de cada trabalhador no processo produtivo. Nesse novo regime de regulação do trabalho, desaparece a figura do fiscalizador na linha de produção (como era de prática no sistema fordista), ou seja, aquele trabalhador que era responsável por fiscalizar e ter certeza de que a produção estava fluindo bem, o qual é substituído pelo o autocontrole. Assim, os próprios funcionários se autocontrolam com 0 aumento de suas responsabilidades, em uma condição que só é possível de ser conseguida se houver um intenso engajamento dos operários quanto aos objetivos da empresa. Este, no entanto, é um imperativo muito mais cruel e eficiente do 
ponto de vista da produtividade, posto que o trabalhador busca cumprir sua meta e se martiriza caso não consiga, ou caso saia algo errado no processo produtivo, acreditando ser um mal trabalhador ou que não tem as competências necessárias para cumprir tal função. Mais uma vez, é possível verificar o caráter perverso existente nas entrelinhas do novo processo empreitado pelo capitalismo.

Para finalizar este tópico, devemos salientar que o Estado tem um papel fundamental na legitimação e na reprodução desse sistema, na medida em que permitiu a flexibilização e desregulamentação das leis trabalhistas para atender as novas "exigências" empresariais. Tais medidas traduzem-se nas legislações que regulamentam o trabalho temporário, o trabalho em tempo parcial, a remuneração por hora trabalhada, a possibilidade de substituição de força de trabalho permanente por estagiários, a hora-extra, entre outras medidas legais.

A seguir, discutiremos sobre a possibilidade das políticas de microcrédito amenizar a situação de precariedade do trabalho enfrentado por uma grande parte dos trabalhadores brasileiros.

\section{O MICROCRÉDITO COMO POSSIBILIDADE PARA AMENIZAR AS SEQUELAS DO PROCESSO DE PRECARIZAÇÃO DO TRABALHO}

O microcrédito caracteriza-se por ser uma modalidade de empréstimos de pequenos valores a juros reduzidos, normalmente menores do que os praticados pelas instituições financeiras. É direcionado, sobretudo, para as pessoas de baixa renda, que não teriam condições de conseguir um empréstimo em uma instituição financeira, seja devido aos juros elevados ou pelas exigências de garantias exigidas pelos bancos.

Outra característica que define bem o microcrédito e o diferencia de uma operação de crédito comum é que ele deve ser investido em atividades que possam gerar renda para a pessoa que o solicita. Em outras palavras, com o crédito, o tomador deve iniciar um comércio, uma prestação de serviços, uma pequena produção, comprar materiais para revenda ou que sirvam de matériaprima, adquirir máquinas que facilitem ou aumentem a eficácia da atividade que 
já realiza, entre outros, ou seja, o microcrédito não é uma operação em que o tomador pode fazer e comprar o que bem entender de acordo com seu livre arbítrio, antes de tudo, é uma operação que busca uma intervenção socioespacial, ao ter como objetivo a liberação do crédito unicamente para que esse seja investido em atividades que possam gerar renda e receita para seus tomadores.

Normalmente, as operações convencionais de crédito em instituições financeiras, não são acessíveis para parte significativa da população, uma vez que exigem comprovação de remuneração mensal (trabalho registrado em carteira) e/ou comprovação contábil de seus rendimentos nos últimos meses. Outra exigência colocada pelas instituições financeiras é a necessidade, por parte dos interessados ao crédito, de predispor ou nomear bens que possam ser utilizados como garantias do pagamento. Salientado isso, destacamos como última característica do microcrédito o fato de cada uma das instituições que trabalham com essa modalidade de crédito possuir métodos próprios para a análise e possível aprovação do crédito, tornando-o um sistema muito mais flexível e facilitando sua liberação. Contrastando radicalmente com as rígidas formas de análise feitas para liberação de crédito praticadas pelas instituições financeiras, o microcrédito se utiliza de uma gama variada de critérios para estabelecer o potencial de pagamento dos possíveis tomadores, sendo que esses critérios podem mudar de acordo com a realidade de cada solicitante. Assim, não apenas registros contábeis ou em carteira de trabalho podem servir como parâmetros para análise do potencial de pagamento, mas também anotações de comercialização feitas em cadernos (sobre venda de produtos e compra de fornecedores, por exemplo), consulta a pontualidade de pagamento a fornecedores, e até mesmo visitas e questionamentos a parentes, vizinhos e pessoas próximas quanto à idoneidade do interessado em obter o crédito (informação obtida junto a um funcionário agente de crédito em 2007).

Dessa forma, podem ser contempladas com o microcrédito pessoas e microempresas que não tenham qualquer tipo de registro e não contribuam a nenhum fundo previdenciário, ou seja, inseridas no setor informal da economia. 
Determinadas organizações que oferecem microcrédito aos trabalhadores informais e microempresas não se restringem apenas a disponibilizar recursos financeiros para apoiar esse público, buscando também trabalhar no sentido de promover o aperfeiçoamento e qualificação desses trabalhadores, oferecendo assistência para empreendimentos, cursos de requalificação e identificação de oportunidades, fomento de grupos de trabalhos formais, entre outras medidas com o objetivo de auxiliar os tomadores (podemos citar como exemplo de instituições de microcrédito que trabalham dessa forma o Banco da Mulher, em Campinas/SP, e o CrediAmigo, com atuação no nordeste, norte de Minas Gerais e Espírito Santo).

Nesse contexto, existe defesa da ideia de que as políticas de oferecimento de microcrédito têm de vir acompanhados de outras iniciativas de apoio a esse público, como citam Toneto Junior e Gremaud:

[...] o microcrédito deve ser combinado com outros instrumentos para ser uma política eficaz. Em vários programas de microcrédito existe uma ligação entre treinamento e crédito, o que facilita a seleção e melhora a capacidade de pagamento (Reinke, 2000). Além de treinamento, muitas vezes são necessárias certas ações para facilitar a inserção dos produtores no mercado - ou seja, o combate à pobreza requer um conjunto integrado de instrumentos. (TONETO JUNIOR; GREMAUD, 2002, p. 97).

Podemos citar diversas organizações que trabalham com o microcrédito: o Banco da Mulher (Paraná, Santa Catarina, Amazonas, Rio de Janeiro, entre outros estados), Portsol (Porto Alegre-RS), Viva-Cred (Rio de Janeiro-RJ), CrediAmigo (atuação na região nordeste e norte de Minas Gerais e Espírito Santo), Instituição de Crédito Solidário de Maringá (Maringá-PR), Centro de Apoio aos Pequenos Empreendimentos da Paraíba, Centro de Apoio aos Pequenos Empreendimentos do Maranhão, Crediconfiança (SC), Banco do Povo Paulista (SP), entre outras instituições. Essas podem ser institucionalizadas em forma de ONGs, (Organização Não Governamental), OSCIPs (Organização da Sociedade Civil de Interesse Público) e Cooperativas de Crédito, ou ainda ser controladas pelas esferas governamentais ou iniciativa privada. 
Mediante a análise das informações levantadas na presente pesquisa, acreditamos ser pertinente a hipótese de que o microcrédito, se bem articulado e planejado por intermédio de políticas públicas, pode cumprir papel importante e auxiliar na busca por um melhor "desenvolvimento socioespacial"3 (SOUZA, 2004) na medida em que contribui para gerar atividades que proporcionem renda e consequentemente o sustento para seus tomadores, aumentando assim a "qualidade de vida e a justiça social".

Assim, acreditamos também que o microcrédito possa ajudar a melhorar a situação degradante que se encontra aquele contingente populacional afetado de forma mais drástica e desumana pelo processo em curso de precarização do trabalho, isto é, aqueles que tiveram menos oportunidades de estudo, aqueles que não encontram outra alternativa a não ser trabalhar no setor informal da economia, alheios a qualquer direito e amparo social, portanto aqueles que, mesmo com o esforço diário de seu trabalho/ocupação (ou procura de trabalho/ocupação), conseguem auferir apenas o mínimo para se manterem vivos.

Porém, o processo de precarização do trabalho é muito amplo, não atacando apenas os desempregados e ocupados em atividades consideradas precárias. Todos os trabalhadores são, de alguma forma, atingidos por esse processo, posto que o novo modelo produtivo iniciado em meados da década de 1970 parece ter como condição de sua existência, para sustentar uma pequena minoria com padrão de vida elevado, a crescente precarização da imensa maioria da população.

\footnotetext{
${ }^{3}$ A grande maioria dos debates sobre o termo desenvolvimento oscila entre o econômico e o social, de forma que Souza (2004) aponta que historicamente existe uma negligência em relação ao espaço nas concepções e discussões sobre desenvolvimento. Para preencher esta lacuna, o autor propõe o conceito de "desenvolvimento sócio-espacial", ao invés de se falar apenas em desenvolvimento social. Para este autor, estamos diante de um autêntico processo de desenvolvimento quando se está diante de uma mudança social positiva, baseada em maior qualidade de vida e aumento da justiça social. A melhoria da qualidade de vida é sucintamente entendida pelo autor como a crescente satisfação das necessidades básicas e não básicas, materiais e imateriais - de um grupo cada vez maior de pessoas. Já o conceito de justiça social é mais amplo, dependendo de lugar para lugar e de acordo com diferentes períodos históricos. No entanto, o autor deixa claro seu ponto de vista sobre a justiça social nos moldes das sociedades capitalistas ocidentais, alegando que os cidadãos devem ter acesso às infraestruturas urbanas, que deve ser garantido não apenas por lei, mas também de forma material, com possibilidade efetiva de acesso, independente da sua condição física ou etnia, partindo-se da premissa da "[...] igualdade dos indivíduos enquanto seres humanos merecedores de tratamento digno e respeitoso". (SOUZA, 2004, p. 62)
} 
Salientamos que o oferecimento de microcréditos enquanto política pública atingiria apenas uma pequena parcela dos atingidos pelo processo de precarização, do qual arriscamos dizer que é justamente a parcela que mais sofre com o processo em curso. Dessa forma, o microcrédito seria apenas um pequeno passo de amenização do processo de precarização do trabalho, para uma parcela específica dos atingidos, sem, contudo, fazer maiores críticas ou propor mudanças sociais radicais do ponto de vista organizacional, que resultem na superação do problema como um todo e na melhoria da qualidade de vida de todos os atingidos. No entanto, "[...] porque dever-se-ia excluir, a priori, a possibilidade de um planejamento que, mesmo operando nos marcos de uma sociedade injusta, contribua, material e político-pedagogicamente, para a superação da injustiça social?" (SOUZA, 2004, p. 29). Assim, de acordo com Souza acreditamos que, o fato de estarmos diante de uma sociedade injusta, não invalida tentativas pontuais de melhora.

\section{CONSIDERAÇÕES FINAIS}

Observamos durante a análise que o processo de precarização do trabalho em curso teve início desde o advento do sistema capitalista de produção. Sofrendo diversas mudanças ao longo dos séculos, podemos notar as diversas formas do capitalismo de se reinventar em sistemas produtivos distintos, com a finalidade de garantir sua reprodução. No entanto, percebemos uma intensificação do processo de precarização do trabalho a partir da década de 1970, com a passagem do sistema fordista para o regime de acumulação flexível. Esse regime demonstra ter como condição básica de sua existência a exploração cada vez maior e cada vez mais cruel dos trabalhadores, utilizando para si as capacidades físicas e também cognitivas da classe trabalhadora, objetivando unicamente auferir maiores lucros.

Esse processo gera uma massa cada vez maior de trabalhadores que se encontra desprovida de qualquer direito trabalhista, na medida em que são excluídos do mercado formal de trabalho. Para estes, resta ocupar os postos de trabalhos mais degradantes e viver a mercê das condições materiais de 
existência que se apresentam no seu cotidiano, posto que batalham todos os dias para conseguir uma ocupação/atividade, mesmo que informal, que possa garantir sua sobrevivência.

Diante desse quadro, acreditamos que, de acordo com as características intrínsecas inerentes ao microcrédito, tais como menores taxas de juros, métodos alternativos e flexíveis de avaliação de potencial de pagamento, possibilidade de treinamento, entre outras características, este possa ser uma possibilidade de alternativa para amenização do processo de precarização do trabalho, sobretudo para aquela camada da população que mais sofre com suas consequências, ou seja, os trabalhadores com baixa escolaridade, menor nível de renda e dependentes diretamente de atividades ligadas ao setor informal da economia.

\section{REFERÊNCIAS}

ALVES, Giovanni. O novo (e precário) mundo do trabalho. Reestruturação produtiva e crise do sindicalismo. SP: Boitempo Editorial, 2005.

FORRESTER, Viviane. O horror econômico. São Paulo: UNESP, 1997.

GORZ, André. Metamorfoses do trabalho. In: . Metamorfoses do trabalho. Crítica da razão econômica. $2^{\circ}$ ed. São Paulo: Annablume, 2001, p. 21-106.

HARVEY, David. Condição pós-moderna. São Paulo: Loyola, 1992.

MARX, Karl. Processo de trabalho e processo de valorização. In: capital: crítica da economia política. São Paulo: Nova Cultura, vol. I, 1996, p. 297-315.

. Manuscritos econômico-filosóficos. São Paulo: Martin Claret, 2006.

As lutas de classes na França de 1848 a 1859. In: MARX, K; ENGELS, F. Obras escolhidas. SP:Alfa-Omega, vol. 1, s/d, p.111-286.

OLIVEIRA, Ana Maria Soares de. A reestruturação produtiva do capital na agroindústria canavieira paulista e os desdobramentos para o trabalho. In: THOMAZ JÚNIOR (Org.). Geografia e trabalho no século XXI. Presidente Prudente/SP: Centelha, 2004, p. 69-104.

POCHMANN, Márcio. O emprego na globalização. A nova divisão internacional do trabalho e os caminhos que o Brasil escolheu. São Paulo: Boitempo Editorial, 2001. 
SINGER, Paul. Globalização e desemprego: diagnósticos e alternativas. São Paulo: Contexto, 2003.

SOUZA, Marcelo Lopes de. Mudar a cidade: uma introdução crítica ao planejamento e à gestão urbanos. 3ª Ed., Rio de Janeiro: Bertrand Brasil, 2004.

STOEF, Ronicley Teurry. Microcrédito no Brasil - o trabalho informal na era dos serviços. II Seminário Ciências Sociais Aplicadas na era dos serviços, $2003 . \quad$ UNIOESTE. Disponível em <http://www.unioeste.br/campi/cascavel/ccsa/llSeminario/trabalhos.html>.

Acesso em: 25 abr. 2009.

TOMELIN, Mario. 0 microcrédito no Brasil. Disponível em $<$ http://www.saa.unito.it/pdf/alfa/tomelin.pdf>. Acesso em: 25 abr. 2009.

TONETO JUNIOR, Rudinei; GREMAUD, Amauri Patrick. Microcrédito e o financiamento rural: recomendações de desenho e gestão a partir da experiência mundial. Planejamento e Políticas Públicas, IPEA, oㅡ 25, p. 90104, jun./dez. 2002.2 Disponível em $<$ http://desafios2.ipea.gov.br/082/08201006.jsp?ttCD CHAVE=2074>. Acesso em: 25 abr. 2009.

THOMAZ JÙNIOR, Antonio. Reestruturação produtiva do capital no campo, no século XXI, e os desafios para o trabalho. Pegada, Presidente Prudente/SP, vol. 5, no 1 e 2, p. 09-30, nov. 2004. Disponível em $<$ http://www4.fct.unesp.br/ceget/PEGADA5152/v5n1e2nov2004.htm>. Acesso em: 20 de nov. 2009.

VASAPOLLO, Luciano. 0 trabalho atípico e precariedade. São Paulo: Expressão Popular, 2005, p. 59-87.

WEBER, Max. A ética protestante e o espírito do capitalismo. 12ª ed., SP: Pioneira, 1997.

WOLLF, Simone. Informatização do trabalho e reificação: uma análise à luz dos programas de qualidade total. Campinas/SP: Editora da UNICAMP; Londrina/ PR: EDUEL, 2005, p. 169-273. 